\title{
Molecular, Chemical and Microscopic Analysis of Medicinal Plant (Cymbopogon distans) from Its Adulterants
}

\author{
Diana Kavidia Muyembe, Dou Rong Kun, Song Zhilei, Fang Jin, Xue Yuan, Piao Yang, Zou Jinjing, \\ Mao Can Quan*
}

School of Life Sciences and Engineering, Southwest Jiaotong University, Chengdu, China

Email address:

maocq@home.swjtu.edu.cn(Mao Can Quan)

${ }^{*}$ Corresponding author

\section{To cite this article:}

Diana Kavidia Muyembe, Dou Rong Kun, Song Zhilei, Fang Jin, Xue Yuan, Piao Yang, Zou Jinjing, Mao Can Quan. Molecular, Chemical and Microscopic Analysis of Medicinal Plant (Cymbopogon distans) from Its Adulterants. Journal of Diseases and Medicinal Plants.

Vol. 4, No. 2, 2018, pp. 35-47. doi: 10.11648/j.jdmp.20180402.11

Received: March 28, 2018; Accepted: April 27, 2018; Published: May 21, 2018

\begin{abstract}
Morphological resemblance among Cymbopogon distans species and their adulterants which are procured from different markets in the form of dried or fresh plant tissues represents a serious problem for quality and safety of medicinal plants, as it supports frauds for substitution. In order to assure the quality control of $C$. distans species, DNA barcode, microscopic identification and High Performance liquid chromatography (HPLC) fingerprint were synergistically used to discriminate $C$. distans from its adulterants. In this work, the internal transcribed spacer 2 (ITS2) was chosen for distinguishing $C$. distans from their usual adulterants from 5 provinces of China. Sequences were obtained after removal of the 5.8S and 28S sections. A multiple sequence alignment was finalized. Results exhibited that ITS2 performed well, with 100\% of genera being accurately distinguished. Additionally, finding indicates that the upper epidermis in leaf of C. citratus was composed of one layer of wide elongated cells called Bulliform cells whereas in $C$. distans the upper epidermis consist of one layer cell, thus these feactures are very important for the anatomy identification. The HPLC fingerprint method was also developed, the similarities of 6 batches of C. distans samples were all more than 0.93 , indicating that the samples from different geographical origins shared similar HPLC fingerprints. And the similarities between C. distans, C. citratus, C. flexuosus and Imperata cylindrica were all less than 0.93, suggesting that there was significance difference between $C$. distans and its adulterants. Finally, it was concluded that the DNA barcode, HPLC fingerprint and microscopic methods could effectively authenticate the quality of $C$. distans from their adulterants and can provide accurate and reliable information to tackle the complex quality issue of $C$. distans in markets. This is the first report of detailed analysis of the $C$. distans for effective quality and safety.
\end{abstract}

Keywords: Internal Transcribed Spacer (ITS2), DNA barcode, Cymbopogon distans, High Performance Liquid Chromatography (HPLC)

\section{Introduction}

Cymbopogon, commonly known as lemongrass in English, is one of the most important medicinal plants of the family Poaceae [1]. The genus Cymbopogon encompasses 140 species mainly distributed in tropical and semi-temperate regions of Asia, South America, Autstralia and Africa. It is extensively recognized for producing high value aromatic oils and important components such as allantoin for industries, which find large use in perfumery, cosmetics, and in the pharmaceutical industries [1-3].
Cymbopogon species exhibits a large variation in morphological characteristics and essential oil composition at inter and intra specific levels [4]. In general, Cymbopogon distans medicinal materials are collected from wild, making its quality of unstable. Traditionally, C. distans and its adulterants were discriminated mainly using morphological characteristics by experienced or trained experts. However, it is somewhat difficult to distinguish them merely based on morphological characteristics [5-8]. It is therefore important to emphasize that the identification of $C$. distans are increasingly being seen as a major challenge, which poses quality problem to both pharmaceutical industries and consumers. Hence, establishing a 
more reliable and accurate method for discriminating C. distans from its adulterants, and illuminating the confusion regarding this medicinal material become urgent and acute. Bearing in mind the adverse effects of adulterants, attention has been shifted to the potential use of DNA barcoding to investigate the extent of adulteration in products.

DNA barcoding is a new molecular diagnostic technique for species identification that has potential to overcome the above mentioned difficulties. Compared with the traditional methods, the DNA barcoding technique gives consistent and reliable outcomes in spite of the age, plant part or environmental factors of the sample [9]. It makes the results more rapid, subjective and accurate. Since its discovery, the power of DNA barcoding has opened up new areas in taxonomic, biological, ecological, and evolutionary research by assisting species identification. In plants, the commonly used primers, namely Internal transcribed spacer (ITS), ITS2, maturase K (matK) gene, ribulose 1,5, bisphosphate carboxylase (rbcL) gene, trnL-F, rpoC1, and (trnH-psbA) Intergenic Spacer have been widely used as potential plant identification and authentication markers for medicinal plant materials, either individually or in combination [10-13]. Recently, Chen and his colleagues [14] have contributed to the DNA barcode database through their recent outstanding research work on the identification of herbal materials based on the ITS2 and psbA-trnH barcodes, and consequently, ITS2 has been validated as a DNA barcode for medicinal plants and psbA-trnH region proposed as a complementary barcode and are now recommended as the universal DNA barcode for plants [15]. At the same time, the China Plant BOL Group [16] analyzed the efficacy of ITS2 as a plant DNA barcode across a huge sample size and also officially recommended that ITS2 regions can serve as a standard plant barcode for distinguishing species. Additionally, the use of high performance liquid chromatography (HPLC) fingerprint emerges to be the popular method utilized in the quality issue of species because of its convenience, large suitability, stability of the sample compound, high accuracy and reproducibility and has been accepted by many organizations U.S. Food [17] and Drug administration [18], and European Medicines Agency [19]for the assessment of the quality of botanical products and as the common method in Chinese pharmacopoeia.

Up to now, most studies of $C$. distans have been focused on the chemical composition of the essential oil of $C$. distans [20-22]. No previous reports have, to the best of authors' knowledge, published regarding the molecular, chemical fingerprint and microscopic analysis of $C$. distans from its adulterants for quality and safety of medicinal plants. In this context, these three techniques were evaluated to identify $C$. distans and its adulterants. The first focus concerns the anatomical and morphology attributes of the leaves of $C$. distans, and differentiates the differences among species. Second, the suitable and feasible DNA barcode were assessed to accurately discriminate between $C$. distans and its adulterants to ensure their safe application in medical use and rational development and utilization, thus providing theoretical basis and data support. Finally, a comprehensive and quantifiable identification HPLC method were developed for the assessment of different batches of $C$. distans species. Additionally, the similarity evaluation between chromatographic fingerprints was carrying out to assure the quality control of $C$. distans.

\section{Materials and Methods}

\subsection{Identification of C. distans by Morphological and Anatomical Analysis}

The fresh plant materials namely $C$. citratus, $C$. distans and C. flexuosus collected from different provinces of China, were identified using the measurement given in flora of China by Chen et al. [25] for morphological and anatomical identification. Briefly, the leaves were segmented and fixed for 24 hours using the standard fixative formaldehyde, acetic acid and ethanol (FAA), embedded in paraffin wax then sectioned [23-24] and stained by flooding them into Ethanol plus $0.8 \mathrm{~g}$ fast green and finally dehydrated back. The slides were analyzed using Light microscope Olympus DP72 China; the objective lenses were (x4, x10 and x25). Microtome QPJ-1B China were used for the segments sectioning, Oven Shanghai China. The reagents used were from Tianjin Zhi Yuan Reagent Co. Ltd. China.

\subsection{Molecular Identification of C. distans}

\subsubsection{Material Collection}

A total of 32 samples including 6 specimens of $C$. distans were gathered from different geographical areas in China, as reported in (Table 1). 15 samples from the three adulterants species of C. citratus, C. flexuosus and Imperata Cylindrica were collected from Yunnan, Anhui, Hebei, Sichuan, Guanxi, and Guangdong Provinces, China (Table 1). The remaining 11 sequences were downloaded from Genbank and the obtained specimens were identified by Song Liangke Associate Professor at the School of Life Science and Engineering, Institute of Southwest Jiaotong University

Table 1. Details of the market samples of C. distans collected in different provinces of China and its adulterants.

\begin{tabular}{llll}
\hline Name of the species & No.of Sample & Origins & Genbank Accession no. of ITS2 \\
\hline Cymbopogon distans & 6 & Yunnan, Sichuan & OUXK11163 http://www.iflora.cn. China \\
$\begin{array}{l}\text { Cymbopogon goeringii } \\
\text { Cymbopogon citratus }\end{array}$ & 3 & Genbank & KF163608.1,KF163609.1,KF163607.1 \\
Cymbopogon flexuosus & 11 & Genbank, Hebei, Guangdong, Yunnan, Anhui, Sichuan & AF019823.1 \\
Cymbopogon martini & 1 & Sichuan, Hebei, Anhui, Guangxi, Genbank & KX828250.1, KX828246.1,KX828244.1, \\
Imperata cylindrica & 2 & Genbank & KX828243.1,KX828245.1 \\
\hline
\end{tabular}




\subsubsection{DNA extraction, PCR Amplification and Sequencing}

DNA from dried leave samples $(30 \mathrm{mg}$ ) was extracted as described by the protocol of Plant Genomic DNA Kit (Tiangen Biotech, Co., Ltd., Beijing, China). The concentration and the purity of DNA were determined electrophoretically by $1.0 \%$ agarose gels. The DNA sample was then diluted to the concentration of $20 \mathrm{ng} / \mu \mathrm{l}$ and stored at $-20^{\circ} \mathrm{C}$. The primers used were as follow: Forward primer: 5'-ATGCGATACTTGGTGTGAAT-3'; and Reverse primer: 5'-GACGCTTCTCCAGACTACAAT-3', the PCR amplification conditions were set as follow: initially at $94^{\circ} \mathrm{C}$ for $5 \mathrm{~min}$; followed by 40 cycles at $94^{\circ} \mathrm{C}$ for $30 \mathrm{~s}, 56^{\circ} \mathrm{C}$ for 30 $\mathrm{s}, 72^{\circ} \mathrm{C}$ for $45 \mathrm{~s}$ with a final extension at $72^{\circ} \mathrm{C}$ for $10 \mathrm{~min}$. The PCR amplification mixtures for ITS2 region was as follows: $25 \mu 1$ of $2 \times$ Tag PCR Master Mix, $8 \mu$ l of genomic DNA, $1 \mu$ of each primer and $15 \mu \mathrm{l}$ of $\mathrm{ddH}_{2} \mathrm{O}$ in a total volume of $50 \mu \mathrm{l}$ (Table 2).PCR amplification of the marker was performed with a thermal cycler (Applied Biosystems). The PCR products were assessed electrophoretically by $1.0 \%$ agarose gels.

Sequences were edited and assembled using clustal W (codon) and refined manually. ITS2 regions were identified and delimited using a website for Hidden Markov Model (HMM) based ITS2 delineation (http://its2.bioapps.biozentrum.uni-wuerzburg.de/). Genetic distances were calculated using the Kimura-2-Parameter (K2P). All the newly obtained ITS2 sequences were uploaded to GenBank. ITS2 sequences were subjected to BLAST (http://www.ncbi.nlm.nih.gov/blast/blast.cgi) for identification of the sequences at species level. The Phylogenetic tree was constructed with the Neighbor-Joining method by using MEGA 5.0; the bootstrapping was done with 1000 replications.

\subsection{HPLC Analysis of C. distans}

\subsubsection{Plant Materials, Sample and Standard Solution Preparation}

The plant materials were collected from different locations as mentioned above (Table 1). As for sample preparation, briefly, each of the collected samples of $C$. distans, $C$. flexuosus, $C$. citratus and Imperata cylindrica was oven-dried until constant weight was reached, and then powdered, sieved through the 40-mesh. $2.0 \mathrm{~g}$ of the powdered samples was precisely weighted and then put into a volumetric flask containing approximately $100 \mathrm{ml}$ of methanol solution for $48 \mathrm{~h}$ the solution was then placed in ultrasonic cleaner for $30 \mathrm{~min}$ and was filtrated through an analytical filter paper and the slurry mixture was centrifuged $(10,000 \mathrm{rpm} / \mathrm{min})$ for $10 \mathrm{~min}$. The supernatant was collected and methanol was added to make the weight lost and finally the sample was filtrated through $0.45 \mu \mathrm{m}$ syringe filter prior to HLPC analysis.

Stock solution was prepared by dissolving accurately weighted standards in absolute methanol. Standard solutions were prepared by serial dilution of the stock solutions to the mobile phase working range of each substance. All of the standard solutions were then stored at $4{ }^{\circ} \mathrm{C}$ and brought to room temperature prior to use. The standard solutions were then filtered through $0.45 \mu \mathrm{m}$ membrane prior to HPLC analysis. The batches number of all the plant materials are presented as follows: 7 species of $C$. citratus (S1-S2) and 6 species of $C$. distans (S15, S16, S17 and S20) were originated from Yunnan province; S3, S9, S13, one species of Imperata cylindrica (S14), and S18 and S19 from Sichuan province; (S4-S5) from Guangzhou Province; S6 and (S10-S11) from Hebei province; S7 and (S12) from Anhui province.

\subsubsection{HPLC Instrumentation and Chromatographic Conditions}

All HPLC analyses were carried out on an Agilent 1260 Series HPLC-DAD system consisting of a vacuum degasser, pumps, auto sampler, column compartment and DAD detector. The conditions of solvent gradient elution was set as follows: 0-10 min, 10\% B-90\% A; 10-15 min, 15\% B-85\% A; $15-35$ min, 30\% B-70\% A; 35-55 min, 55\% B-45\% A; 55-60 min, 80\% B-20\% A; 60-70 min, 100\% B-0\% A. During the experiment, the chromatogram was monitored at a wavelength of $224 \mathrm{~nm}$ and the column temperature was kept at $30^{\circ} \mathrm{C}$, while the injection volume of each sample and standard solution was $10 \mu \mathrm{L}$. The HPLC mobile phase consisted of B acetonitrile $-\mathrm{A}$ $0.1 \%$ phosphoric acid, $\mathrm{pH}: 3$ at a flow rate of $0.8 \mathrm{~mL} / \mathrm{min}$; was prepared fresh daily, filtered then degassed prior to injecting.

\subsubsection{Validation Procedure}

The calibration curves were calculated by plotting the peak area (y) versus nominal concentration of each analyte (x) and were fitted to a linear function of type $y=a x+b$. The limit of detection (LOD) was evaluated as the minimum concentration of the compounds required to produce signals. Several analytical parameters were assessed to validate the HPLC method, i.e., based on the recommendations of $\mathrm{ICH}$ (International Council for Harmonization) guidelines for method validation. The accuracy tests were carried out by spiking the known contents of mixed standard solution into the known concentration of $C$. distans samples, and the evaluation was completed by analyzing the three different spiking concentrations of analytes in triplicates. The percent recovery rates for the analytes were presented as mean $(100 \%)$.

\subsubsection{Data Analysis}

All determinations were conducted in triplicates with data reported as mean \pm standard deviation. While the data analysis was carried out using the SOP of Similarity Evaluation System for Chromatographic Fingerprint of TCM (Version 2004A) which was developed by Chinese Pharmacopoeia Committee. This software assesses similarity based on correlative coefficient calculations for fingerprint chromatograms. Hierarchical cluster analysis (HCA) was carried out using SPSS software version 16, USA. The peaks areas of all the samples of $C$. distans were systematically clustered and the Ward method and Squared of the Euclidean distance were selected as a measure of similarity between samples of different batches. Reference chromatogram $\mathrm{R}$ was regenerated 
with the aid of fingerprint chromatogram similarity calculation software.

\section{Results}

\subsection{Microscopic Identification}

The morphological characteristics were done by examining the species with naked eye and the leaf blade of all the samples was measured using a ruler and the mean was evaluated based on the width and length of the leaf blade. In the current study the morphological and anatomical features were used based on the description given in Flora of China (http://frps.eflora.cn/) [25].

The results demonstrate that the color of fresh species of $C$. distans was dark green color on upper and lower surface and the color of dried species $C$. distans was green pale with leaf blades narrowly linear, folded with a softer texture. The length and width of 6 species of $C$. distans were in the range of 35 to $50 \mathrm{~cm}$, and from 1.7 to $4 \mathrm{~mm}$, respectively (Figure 1C). $C$. citratus has simple leaf, alternate and linear. Their length and width were in the range of 62 to $70 \mathrm{~cm}$ and from 2 to $5 \mathrm{~mm}$, respectively while having sheathed and apex acute (Figure $1 \mathrm{~A})$; it has a color of light green on upper and lower surface and has an entire margin and parallel venation compared with the morphology of $C$. flexuosus as the leaves length range from 82 to $120 \mathrm{~cm}$, and the width from 5-19 mm (Figure 1B). The leaves size of $C$. distans was smaller than $C$. citratus and C. flexuosus, the venation of $C$. citratus and C. flexuous was parallel but the venation of $C$. distans was folded while the length and the width of Imperata cylindrica range from 50 to $100 \mathrm{~cm}$ and from $0.8-2 \mathrm{~cm}$, respectively (Figure 1D).

In addition, the anatomy characteristic of $C$. distans show that upper epidermis in $C$. distans is built of one layer of miniature cells whereas upper epidermis in C. citratus gives one layer of wide cells. Both species possess mesophyll tissue and the spongy parenchyma is constituted of 1-2 layers in $C$. citratus followed by the upper epidermis, while the lower epidermis in $C$. distans is constituted of one layer of small cell following by the spongy mesophyll that is situated between vascular bunbles (Figure $2 \mathrm{C}$ ). The vascular bundles in $C$. citratus are surrounded by 1-2 layers of sclerencyma cells but in $C$. distans the vascular bundles are covering by 2-3 layers of sclerencyma cells. The lower epidermis is formed of a layer of small cells in $C$. citratus followed by the vascular bundles (Figure 2A, B). This study demonstrated that the morphology and anatomy characteristics of the species of $C$. distans could be primarily discriminated from its adulterants (Table 2)
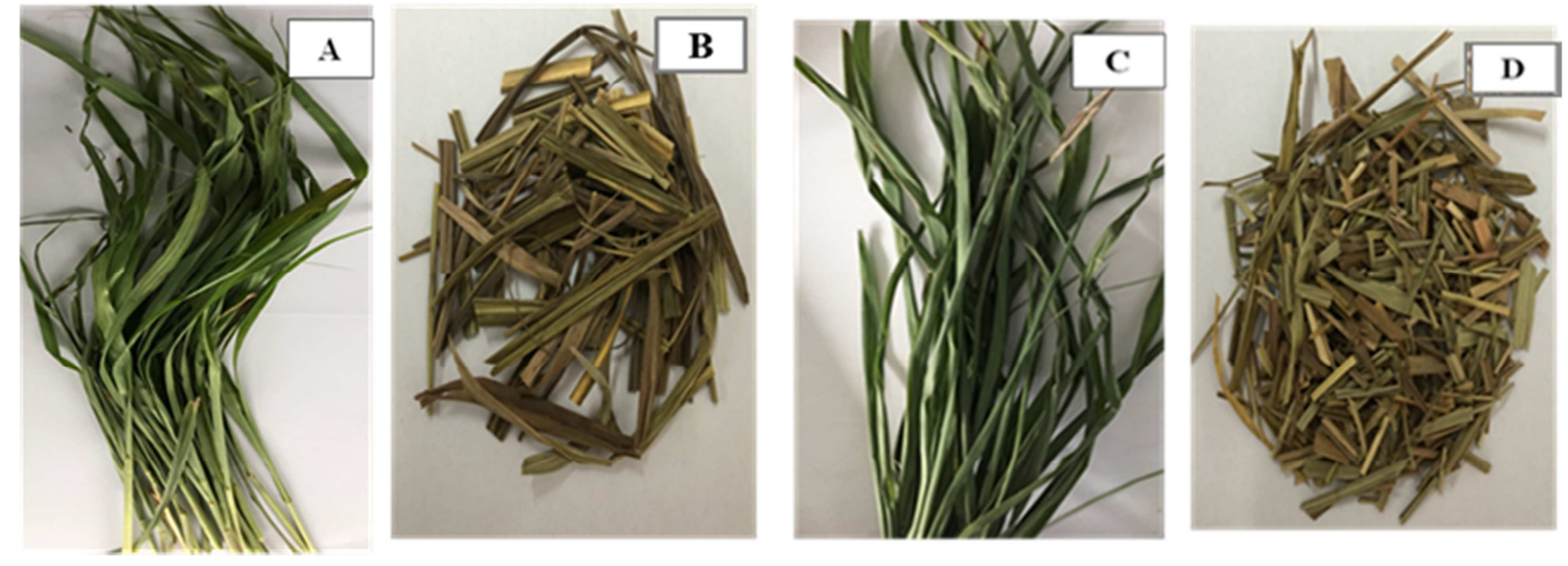

Figure 1. Morphologies traits of C. citratus (A), C. flexuosus (B), C. distans (C) andImperata cylindrica (D) (Photograph taken by Kavidia Muyembe Diana).
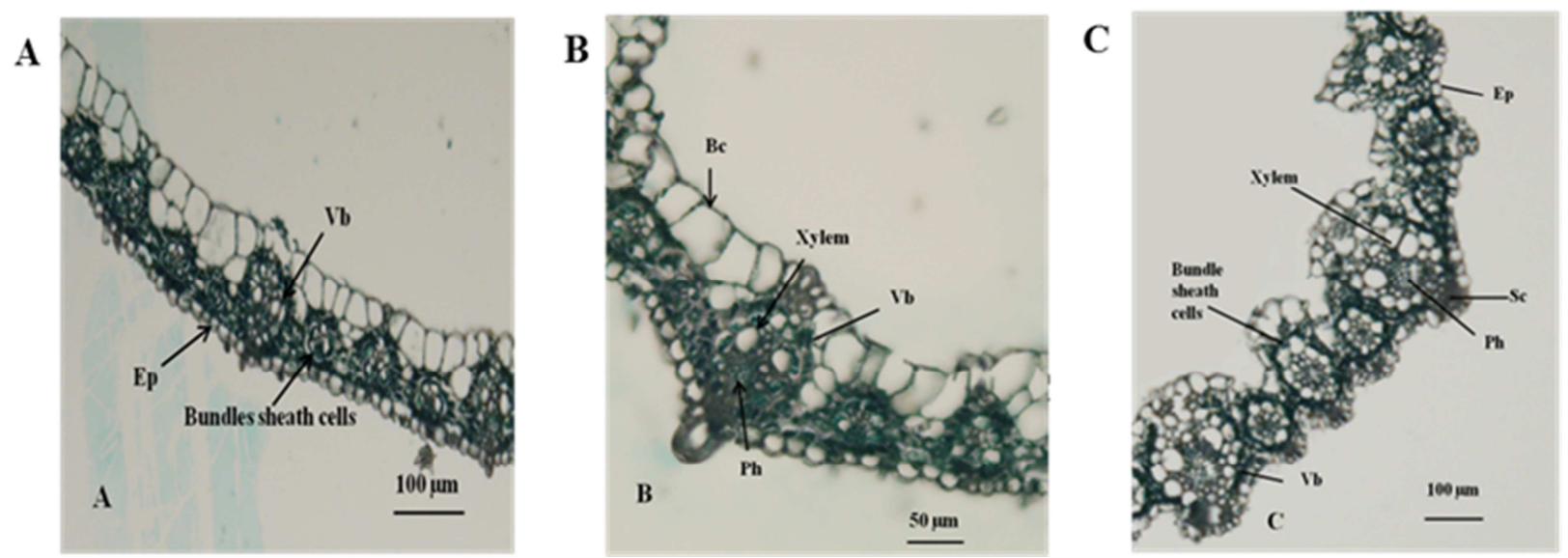

Figure 2. The cross section of the leaf of $C$. distans $(C)$ and leaf section of $C$. citratus $(A, B)$ shows, xylem $(x)$ and phloem (p), epidermis (ep), bundle sheath cells and vascular bundles (vb) bulliform cells (bc). 
Table 2. Comparatively morphological characteristics of $C$. distans and its adulterants.

\begin{tabular}{|c|c|c|c|c|}
\hline & C. citratus (A) & & C. distans (C) & \\
\hline Characteristics & Sample & Flora of China & Sample & Flora of China \\
\hline Leaf shape & Linear & linear-lanceolate & Narrow linear & Narrow linear \\
\hline Leaf size/Length/width & $62-70 \mathrm{~cm} / 2-5 \mathrm{~mm}$ & $30-90 \mathrm{~cm} / 5-15 \mathrm{~mm}$ & $35-50 \mathrm{~cm} / 1.7-4 \mathrm{~mm}$ & $10-30(-50) \mathrm{cm} / 1.5-5 \mathrm{~mm}$ \\
\hline Venation & Parallel & Parallel & Folded & flattened or folded \\
\hline Color & Light green & pale green & Dark green & \\
\hline
\end{tabular}

Table 2. Continued.

\begin{tabular}{lllll}
\hline & C. flexuosus (B) & & Imperata cylindrica (D) & Flora of China \\
\hline Characteristics & Sample & Flora of China & Sample & Narrow linear \\
\hline Leaf shape & Linear & Linear & Narrow linear & $20-100 \mathrm{~cm} / 0.8-2 \mathrm{~cm}$ \\
Leaf size/Length/width & $82-120 \mathrm{~cm} / 5-1.9 \mathrm{~cm}$ & Up to $100 \mathrm{~cm} / 1.5 \mathrm{~cm}$ & $50-100 \mathrm{~cm} / 0.8-2 \mathrm{~cm}$ & Parallel \\
Venation & Parallel & Parallel & Parallel & \\
Color & Pale green & & Pale green & \\
\hline
\end{tabular}

\subsection{DNA Barcode Analysis}

\subsubsection{Sequence Analysis}

In the current study, the efficiency of the PCR amplification of ITS2 region was $100 \%$. Moreover, the candidate barcode region was successfully sequenced by $100 \%$. All of the sequencing outcomes were submitted to the Genbank database. The variations in the ITS2 sequences among $C$. distans and its potential adulterants were assessed. The ITS2 sequences length of $C$. distans was $219 \mathrm{bp}$. Furthermore, the other three common adulterants, $C$. citratus, C. flexuosus and Imperata cylindrica were between 219 to $224 \mathrm{bp}$ in length. The guanine-cytosine (GC) content of the $C$. distans was $71.23 \%$ while the other three adulterants displayed GC contents which ranged from 71.4 to $73.1 \%$ (Table 3 ).

Identification of polymorphic sites of ITS2 sequences exposed a significant sequence variation between $C$. distans and its adulterants species. One polymorphic site was identified between $C$. distans and C. flexuosus (position 48) and 5 indels (positions 23, 37-40) were identified in the alignment between these two species, five polymorphic sites were found between $C$. distans and $C$. citratus (positions $33,51,134,170,194)$ (Table 4), while 9 polymorphic sites were located between $C$. distan and imperata cylindrica at the positions $(33,55,62,104,154,163,175,177$ and 204), two polymorphic sites were identified between $C$. distans and $C$. georigii (positions 48, 196) and 4 indels (positions 37-40), There were no mutation among $C$. distans and $C$. flexuosus, whereas two mutations A-C and A-C were identified in $C$. citratus ITS2 sequences at the position 208 and 160, respectively.

Table 3. ITS2 Sequences length and CG content \% of C. distans sample and its closely related species.

\begin{tabular}{lllll}
\hline Sample No. & Species & & Sequence length bp & CG content \% \\
\hline & & Sample size & ITS2 & 72.15 \\
\hline 1 & C. citratus & 9 & 219 & 71.23 \\
2 & C. distans & 6 & 219 & 71.1571 .43 \\
3 & C. flexuosus & 11 & 223 224 & 70.85 _70.09 \\
4 & C. georigii & 3 & 223224 & 71.36 \\
5 & C. martini & 1 & 220 & 73.06 \\
6 & Imperata cylindrica & 2 & 219 & \\
\hline
\end{tabular}

Table 4. Single nucleotide polymorphisms of ITS2 DNA sequences among C. distans and its adulterants.

\begin{tabular}{lccccccccccccccccccccc}
\hline Species & $\mathbf{2 3}$ & $\mathbf{3 3}$ & $\mathbf{3 7}$ & $\mathbf{3 8}$ & $\mathbf{3 9}$ & $\mathbf{4 0}$ & $\mathbf{4 8}$ & $\mathbf{5 1}$ & $\mathbf{5 5}$ & $\mathbf{6 2}$ & $\mathbf{1 0 4}$ & $\mathbf{1 3 4}$ & $\mathbf{1 5 4}$ & $\mathbf{1 6 3}$ & $\mathbf{1 7 0}$ & $\mathbf{1 7 5}$ & $\mathbf{1 7 7}$ & $\mathbf{1 9 4}$ & $\mathbf{1 9 6}$ & $\mathbf{2 0 4}$ \\
\hline C. distans & - & $\mathrm{T}$ & - & - & - & - & $\mathrm{T}$ & $\mathrm{T}$ & $\mathrm{C}$ & $\mathrm{T}$ & $\mathrm{T}$ & $\mathrm{A}$ & $\mathrm{T}$ & $\mathrm{A}$ & $\mathrm{C}$ & $\mathrm{C}$ & $\mathrm{A}$ & $\mathrm{T}$ & $\mathrm{G}$ & $\mathrm{A}$ \\
C. flexuosus & $\mathrm{C}$ & $\mathrm{T}$ & $\mathrm{T}$ & $\mathrm{A}$ & $\mathrm{G}$ & $\mathrm{G}$ & $\mathrm{C}$ & $\mathrm{T}$ & $\mathrm{C}$ & $\mathrm{T}$ & $\mathrm{T}$ & $\mathrm{A}$ & $\mathrm{T}$ & $\mathrm{A}$ & $\mathrm{C}$ & $\mathrm{C}$ & $\mathrm{A}$ & $\mathrm{T}$ & $\mathrm{G}$ & $\mathrm{A}$ \\
C. citratus & - & $\mathrm{G}$ & - & - & - & - & $\mathrm{T}$ & $\mathrm{C}$ & $\mathrm{C}$ & $\mathrm{T}$ & $\mathrm{T}$ & $\mathrm{G}$ & $\mathrm{T}$ & $\mathrm{A}$ & $\mathrm{T}$ & $\mathrm{C}$ & $\mathrm{A}$ & $\mathrm{A}$ & $\mathrm{G}$ & $\mathrm{A}$ \\
Imperata cylindrica & - & $\mathrm{G}$ & - & - & - & - & $\mathrm{T}$ & $\mathrm{T}$ & $\mathrm{A}$ & $\mathrm{C}$ & $\mathrm{C}$ & $\mathrm{A}$ & $\mathrm{C}$ & $\mathrm{G}$ & $\mathrm{C}$ & $\mathrm{T}$ & $\mathrm{T}$ & $\mathrm{T}$ & $\mathrm{G}$ & $\mathrm{C}$ \\
C. georigii & - & $\mathrm{T}$ & $\mathrm{T}$ & $\mathrm{A}$ & $\mathrm{G}$ & $\mathrm{G}$ & $\mathrm{C}$ & $\mathrm{T}$ & $\mathrm{C}$ & $\mathrm{T}$ & $\mathrm{T}$ & $\mathrm{A}$ & $\mathrm{T}$ & $\mathrm{A}$ & $\mathrm{C}$ & $\mathrm{C}$ & $\mathrm{A}$ & $\mathrm{T}$ & $\mathrm{A}$ & $\mathrm{A}$ \\
C. martinii & - & $\mathrm{A}$ & & & & & $\mathrm{T}$ & $\mathrm{C}$ & $\mathrm{C}$ & $\mathrm{T}$ & $\mathrm{T}$ & $\mathrm{A}$ & $\mathrm{T}$ & $\mathrm{A}$ & $\mathrm{C}$ & $\mathrm{C}$ & $\mathrm{T}$ & $\mathrm{T}$ & $\mathrm{G}$ & $\mathrm{A}$ \\
\hline
\end{tabular}

\subsubsection{The K2P Genetic Distance}

The genetic distance matrix based on the ITS sequences was computed according to the Kimuna 2- parameter model (K2P) (Table 5). The K2P genetic distances among C. citratus species was 0.000 to 0.009 with an average distance of 0.002 , meanwhile the genetic distance among $C$. distans was zero.
The distance between $C$. distans and $C$. flexuosus ranged from 0 to 0.005 , with an average distance of 0.002 . And the distance between $C$. distans and $C$. citratus ranged from 0.000 to 0.033 with an average distance of 0.013 . The inter-specific distance between $C$. distans and its adulterant ranged from 0.002 to 0.016 with an average distance of 0.006. Results also 
displayed that the minimum inter-specific K2P distances between $C$. distans and its adulterant were larger than the maximum intra-specific distance among $C$. distans (Table 5). According to the Neighbor-Joining (NJ) tree (Figure 3), $C$. distans and its adulterants could be placed in genus
Cymbopogon and differentiated from most of the other genera, whereas $C$. distans and its adulterants could be distinguished from each other based on the sequence divergences. Phylogenetic analysis using ITS2 sequences clearly distinguished the $C$. distans and the closely related species.

distinguished the $C$. distans and the clos
distances between $C$. distans and its adulterants.

\begin{tabular}{llll}
\hline Specie5 & K2Pdistance & Average \\
\hline C. distans & $0.000-0.000$ & 0 \\
C. flexuosus & $0.000-0.000$ & 0 \\
C. citratus & $0.000-0.009$ & 0.002 \\
C. distans_C. flexuosus & $0.000-0.005$ & 0.002 \\
C. distans_C. citratus & $0.000-0.033$ & 0.013 \\
C. distans and its adulterants & $0.002-0.016$ & 0.006 \\
C.distans and closely related species & $0.005-0.034$ & 0.011 \\
\hline
\end{tabular}

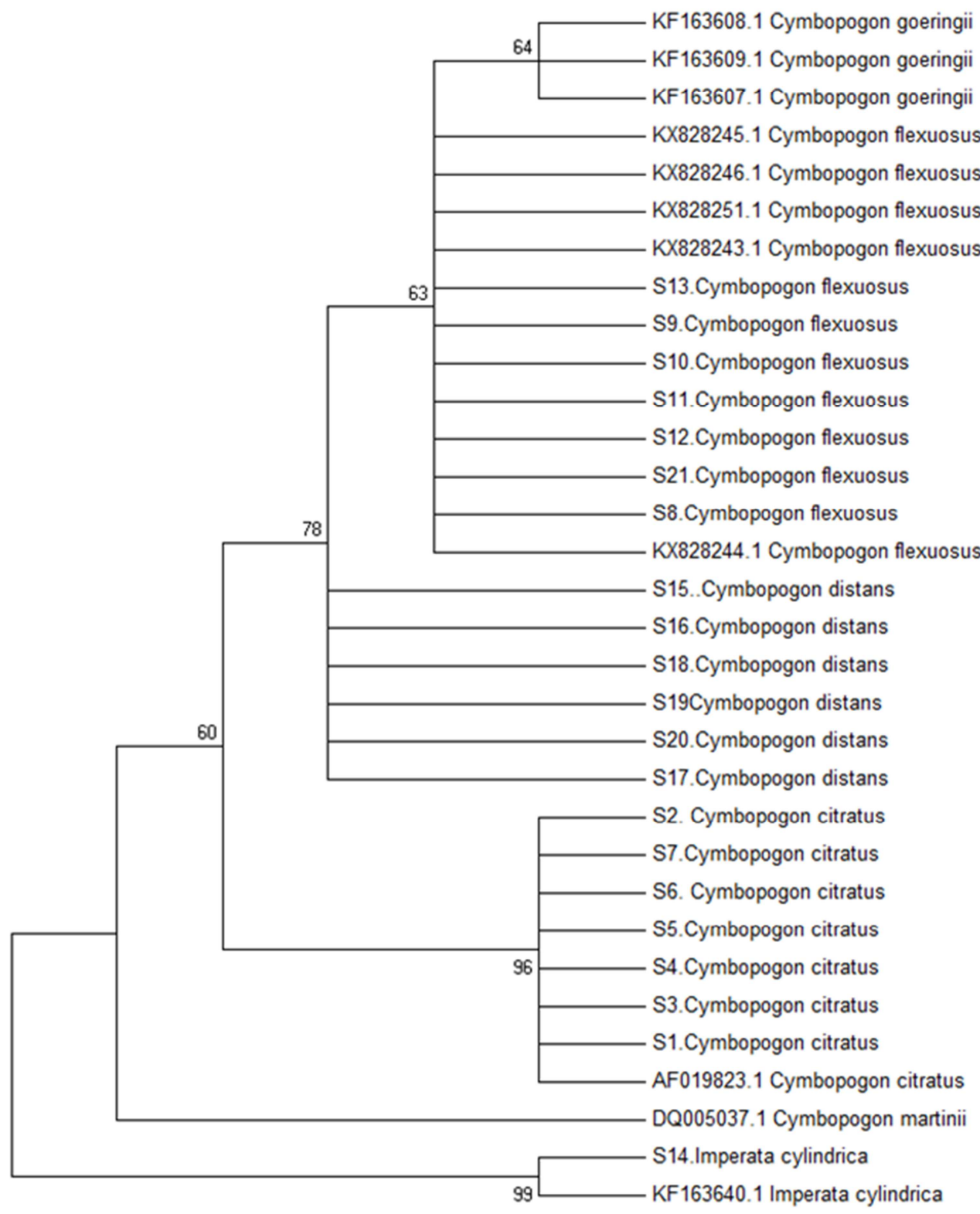

\subsection{5}

Figure 3. Phylogenetic tree of the family Poaceae constructed with the ITS2 sequences by using the Neighbor-Joining method. 


\subsection{HPLC Fingerprint Analysis}

\subsubsection{Establishment of Fingerprint Chromatograms for $C$. distans and Its Adulterants}

Twenty tested samples solutions were prepared as described above in the section 3.1, and the samples solutions were submitted to the same chromatography conditions as reported in the section 3.3, and chromatograms of all samples were recorded for 70 minutes. The finding demonstrates that 30, 27 and 21 peaks were common fingerprint among six samples of C. distans, seven batches of C. citratus, and six bactches of $C$. flexuosus, respectively (Figure 4, 7A, 7B, 7C). In addition, the reference chromatogram fingerprint of $C$. distans showed that the content composition of $C$. distans was quite different from its closely related species (Figure 7A). The total of 16 peaks in $C$. distans were different from its closely related species
(Figure 6); and peak No. 1, 5-7, 11-19, 21-24, and No. 30 can be used to discriminate the species of $C$. distans from it closely related species as well as its adulterants and 14 peaks were common between the three references chromatogram of C. distans, C. citratus and C. flexuosus, these common peaks showed the similarity between them and these peaks can be used to classified them into closely related species (Table 9) (Figure 5,7D)., Furthermore, the data analysis was carried out using the SOP of Similarity Evaluation System for Chromatographic Fingerprint of TCM (Version 2004A) which was developed by Chinese Pharmacopoeia Committee, produced reference chromatogram R. Reference chromatogram $\mathrm{R}$ was regenerated with the aid of fingerprint chromatogram similarity calculation software.
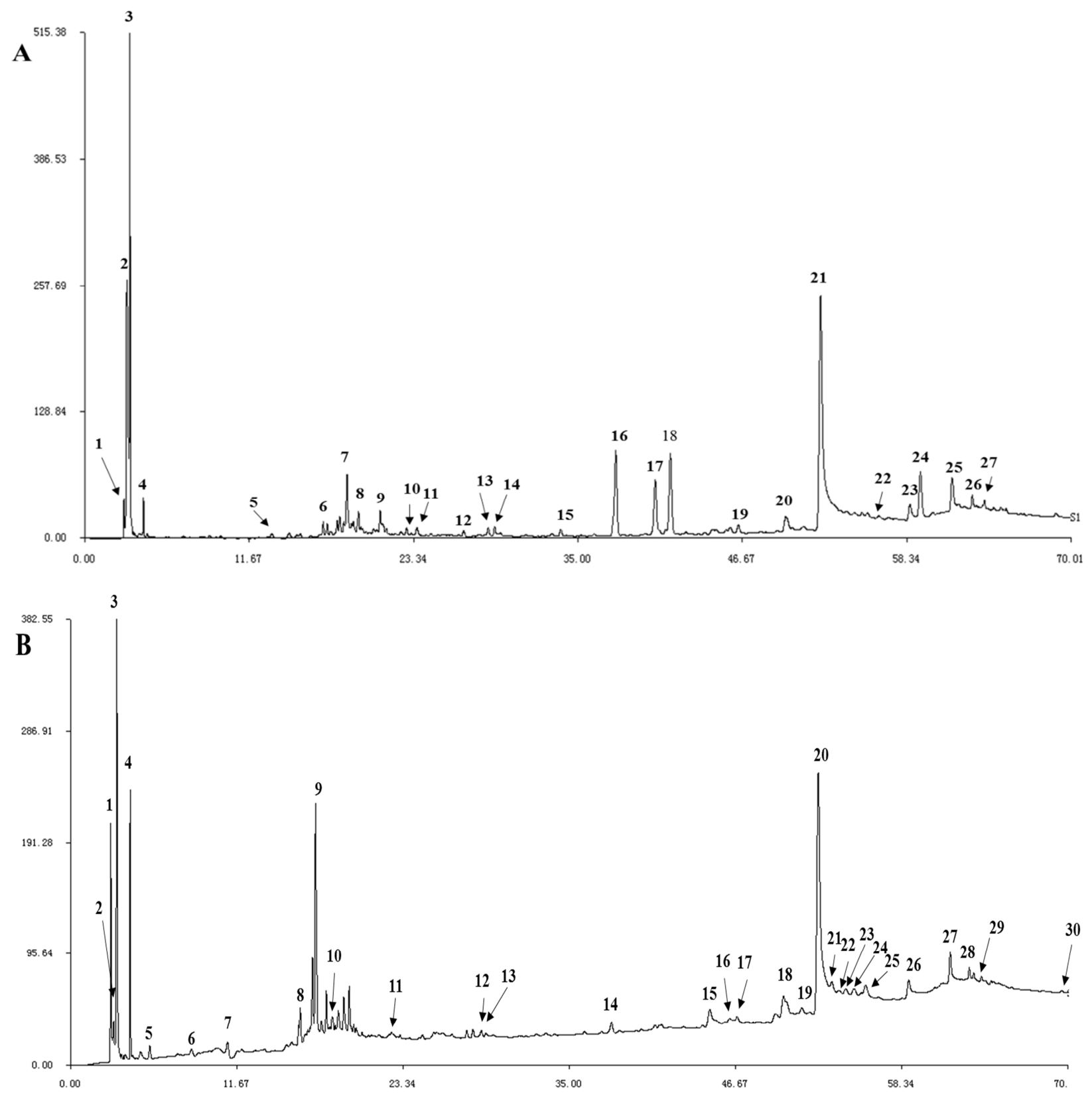


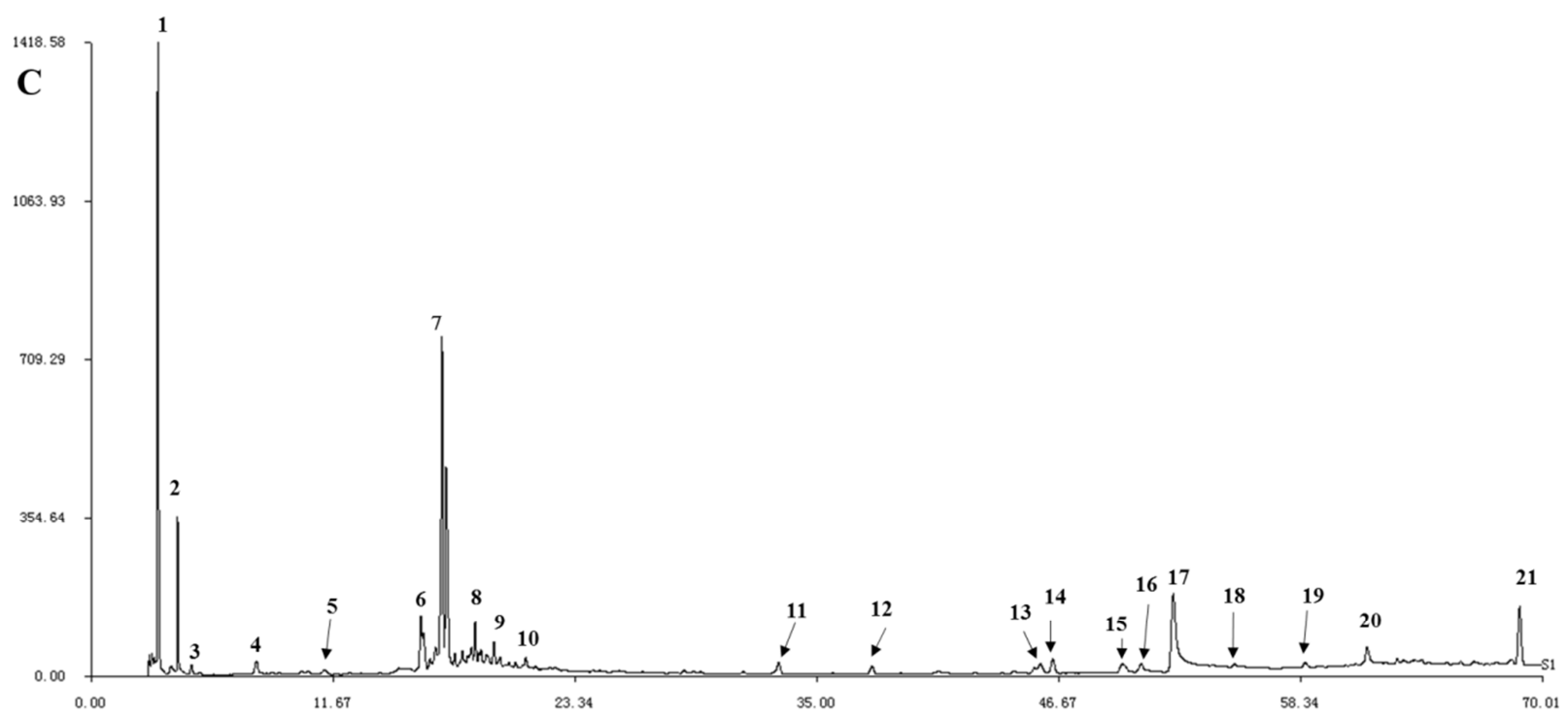

Figure 4. Reference fingerprint chromatogram of C. citratus (A) 27 commons peaks were identified among six batches of C.citratus, the reference fingerprint chromatogram of $C$. distans (B) 30 common peaks were identified, the reference fingerprint of $C$. flexuosus $(C) 21$ common peaks were identified.

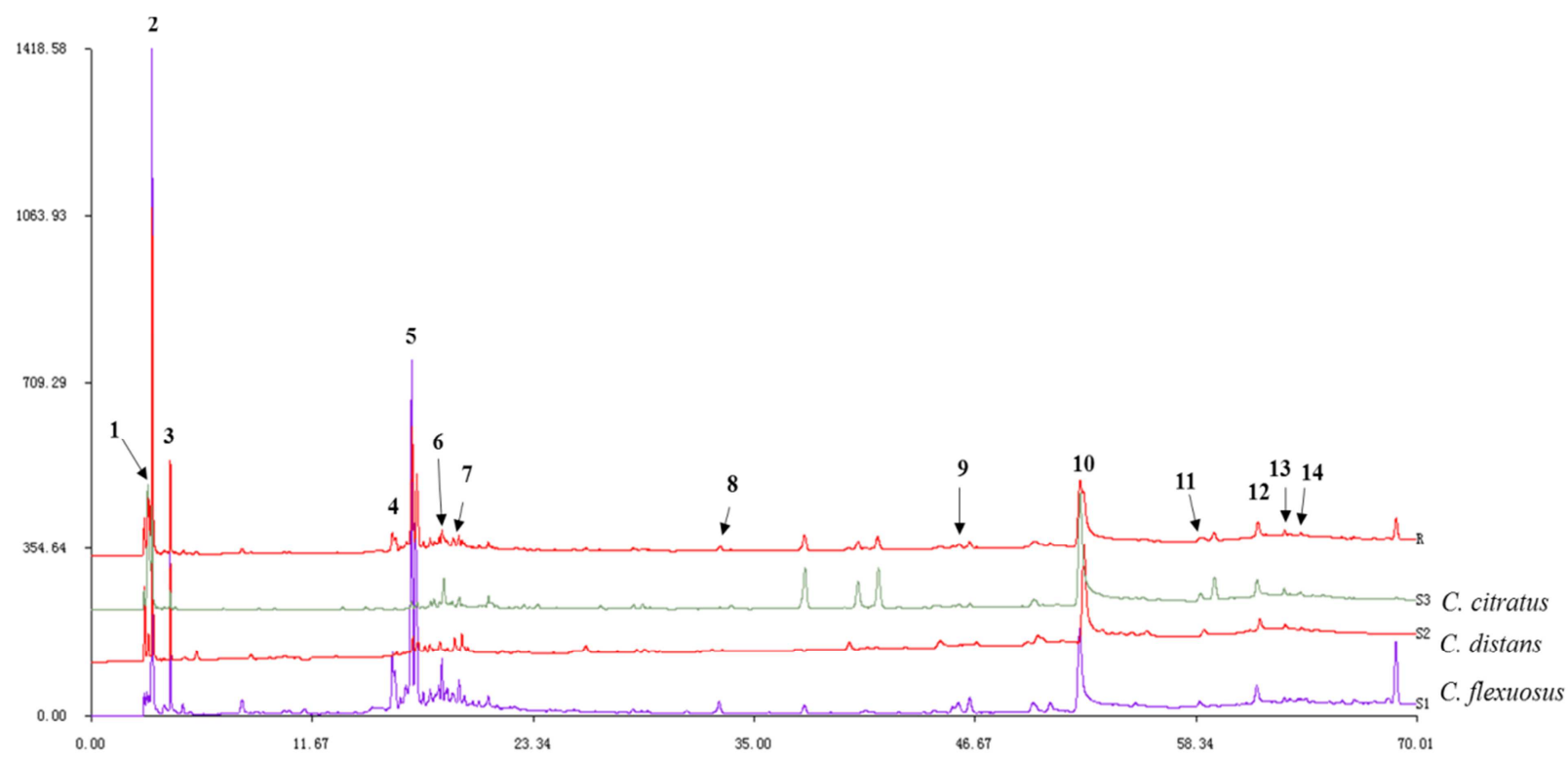

Figure 5. The reference chromatogram of batches of C. distans, bacthes of $C$. citratus and batches of C. flexuosus, 14 peaks were common between them.

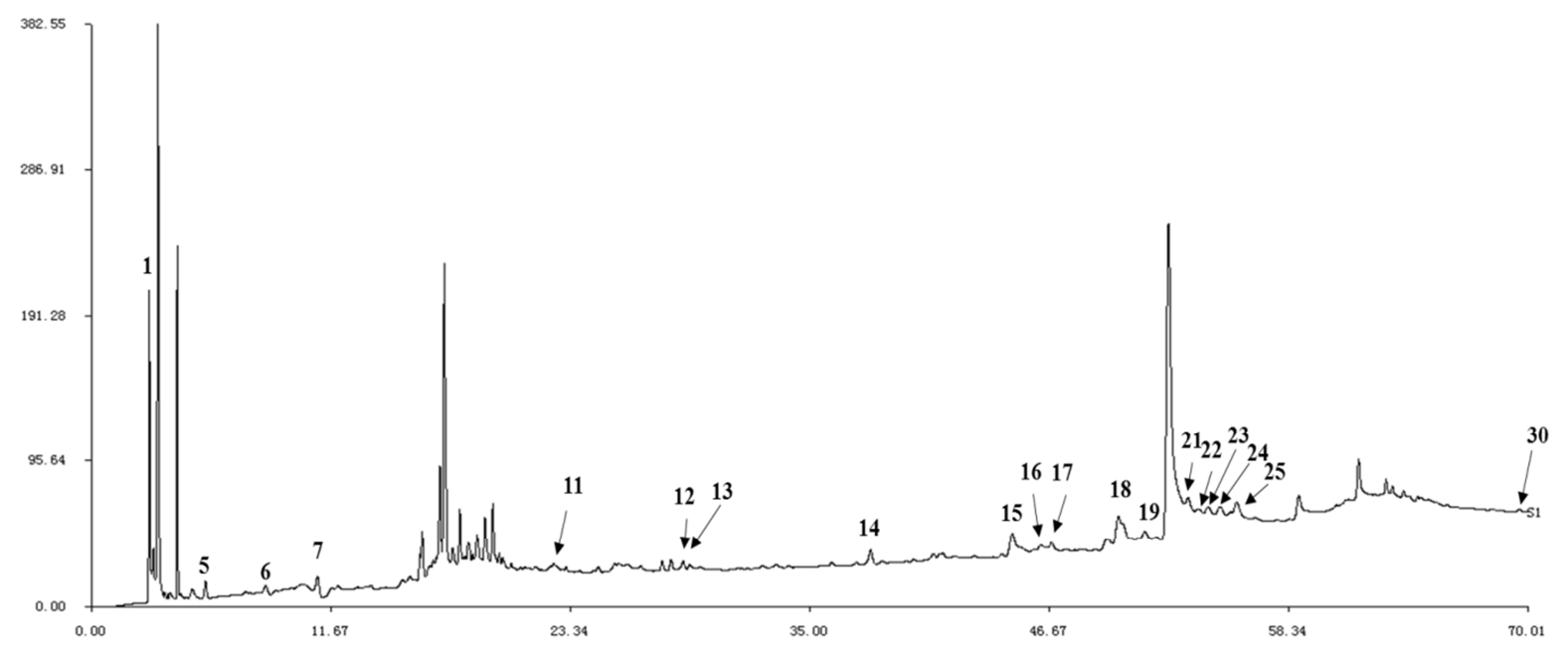

Figure 6. The reference fingerprint of $C$. distans indicate the 16 different peaks found in C. distans. 


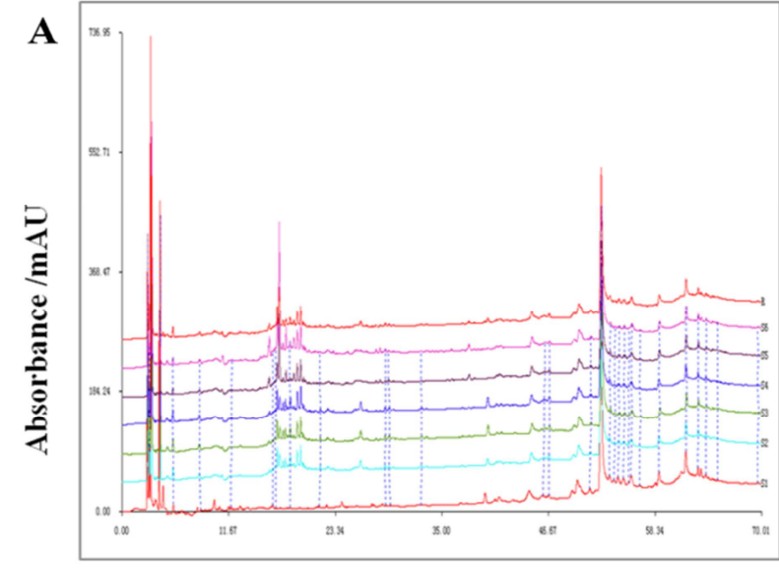

Retention time/min

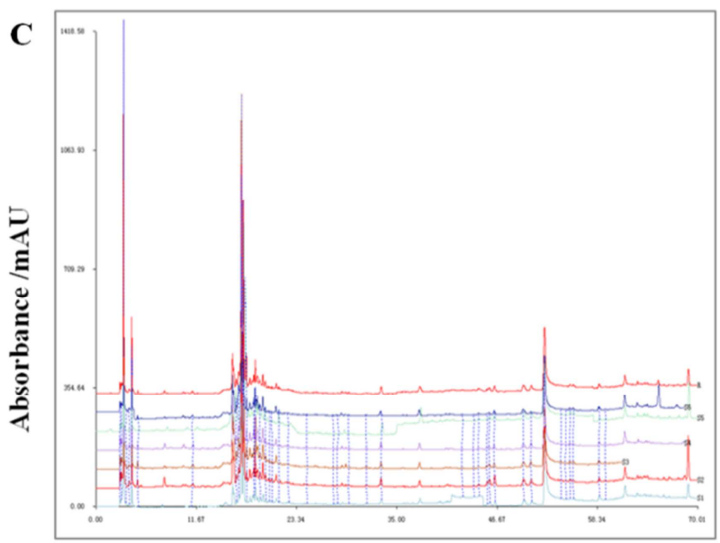

Retention time/min

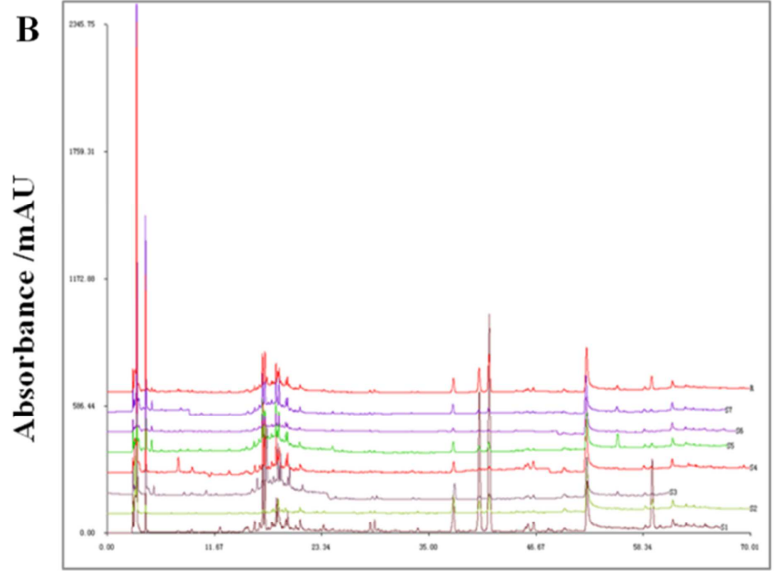

Retention time/min

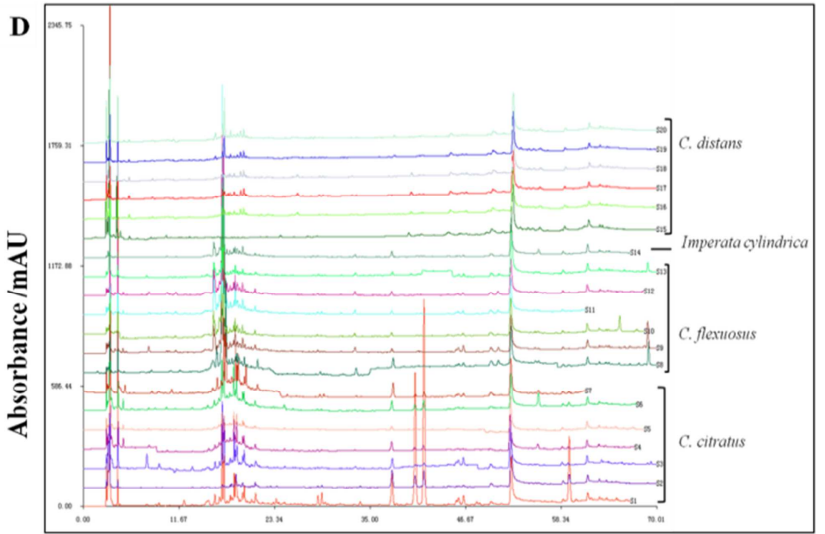

Retention time/min

Figure 7. HPLC fingerprint measured at UV $224 \mathrm{~nm}$ of six samples of C. distans (A), seven lots of C. citratus (B), six samples of C. flexuosus (C), and C. distans and its adulterants $(D)$.

\subsubsection{Similarity Assessment}

Findings from the fingerprint chromatograms analysis of 7 batches $C$. citratus indicate that the similarity indexes obtained from 27 common peaks were $>0.91$ for 5 samples and the similarity of 2 samples with batches number $\mathrm{S} 1$ and $\mathrm{S} 2$ were $<0.91$ (Table 7) (Figure 7B). The fingerprint chromatograms analysis of 6 batches of $C$. flexuosus show that the similarity indexes obtained from 21 common peaks were more than 0.93 for all the samples (Table 8) (Figure 7C). The fingerprint chromatograms analysis of 6 batches $C$. distans displayed that the similarity indexes obtained from 30 common peaks were $>0.91$ (Table 6) (Figure 7A), except the S15 which had the value of less than 0.91. Finally, the similarity indexes between species of $C$. distans, $C$. citratus, $C$. flexuosus and Imperata cylindrica were all less than 0.93
(Table 9). Thus, it could be concluded that, 7 samples of $C$. citratus from different provinces, in which 5 samples originating from Guangdong, Hebei, Anhui and Sichuan shared similar HPLC fingerprints and the internal qualities of the two samples of C. citratus S1 and S2 from Yunnan province were unstable. While, the quality of the six samples of C. flexuosus from Guangxi, Sichuan, Hebei, Anhui shared similar HPLC fingerprints among them. From the six samples of $C$. distans, one sample S15 collected in Sichuan Province was not stable and the quality of the other 5 samples of $C$. distans collected from different geographical origins shared similar HPLC fingerprints. Finally, the similarity evaluation of the twenty collected samples (Table 9) shows a significant difference between $C$. distans and its adulterants.

Table 6. The similarity evaluation of $C$. distans from different provinces.

\begin{tabular}{llllllll}
\hline No. & S15 & S16 & S17 & S18 & S19 & S20 & Reference \\
\hline S15 & 1.000 & 0.827 & 0.828 & 0.834 & 0.833 & 0.754 & 0.890 \\
S16 & 0.827 & 1.000 & 0.997 & 0.991 & 0.983 & 0.962 & 0.990 \\
S17 & 0.828 & 0.997 & 1.000 & 0.992 & 0.977 & 0.953 & 0.988 \\
S18 & 0.834 & 0.991 & 0.992 & 1.000 & 0.977 & 0.940 & 0.986 \\
S19 & 0.833 & 0.983 & 0.977 & 0.977 & 1.000 & 0.968 & 0.987 \\
S20 & 0.754 & 0.962 & 0.953 & 0.940 & 0.968 & 1.000 & 0.956 \\
Reference & 0.890 & 0.99 & 0.988 & 0.986 & 0.987 & 0.956 & 1.000 \\
\hline
\end{tabular}


Table 7. Similarity evaluation of 7 lots of $C$. citratus from different provinces.

\begin{tabular}{lllllllll}
\hline No. & S1 & S2 & S3 & S4 & S5 & S6 & S7 & Reference \\
\hline S1 & 1.000 & 0.546 & 0.499 & 0.512 & 0.531 & 0.486 & 0.493 & 0.731 \\
S2 & 0.546 & 1.000 & 0.56 & 0.792 & 0.572 & 0.676 & 0.492 & 0.719 \\
S3 & 0.499 & 0.560 & 1.000 & 0.865 & 0.953 & 0.941 & 0.958 & 0.930 \\
S4 & 0.512 & 0.792 & 0.865 & 1.000 & 0.881 & 0.916 & 0.847 & 0.914 \\
S5 & 0.531 & 0.572 & 0.953 & 0.881 & 1.000 & 0.976 & 0.989 & 0.951 \\
S6 & 0.486 & 0.676 & 0.941 & 0.916 & 0.976 & 1.000 & 0.956 & 0.943 \\
S7 & 0.493 & 0.492 & 0.958 & 0.847 & 0.989 & 0.956 & 1.000 & 0.927 \\
Reference & 0.731 & 0.719 & 0.930 & 0.914 & 0.951 & 0.943 & 0.927 & 1.000 \\
\hline
\end{tabular}

Table 8. The similarity of the chromatographic patterns obtained from the 6 samples of C. flexuosus.

\begin{tabular}{llllllll}
\hline No. & S8 & S9 & S10 & S11 & S12 & S13 & Reference \\
\hline S8 & 1.000 & 0.907 & 0.883 & 0.893 & 0.849 & 0.900 & 0.934 \\
S9 & 0.907 & 1.000 & 0.951 & 0.959 & 0.868 & 0.931 & 0.973 \\
S10 & 0.883 & 0.951 & 1.000 & 0.989 & 0.856 & 0.978 & 0.982 \\
S11 & 0.893 & 0.959 & 0.989 & 1.000 & 0.886 & 0.982 & 0.990 \\
S12 & 0.849 & 0.868 & 0.856 & 0.886 & 1.000 & 0.875 & 0.919 \\
S13 & 0.900 & 0.931 & 0.978 & 0.982 & 0.875 & 1.000 & 0.981 \\
Reference & 0.934 & 0.973 & 0.982 & 0.990 & 0.919 & 0.981 & 1.000 \\
\hline
\end{tabular}

Table 9. The similarity of the chromatographic patterns obtained from the 20 samples from different provinces.

\begin{tabular}{llll}
\hline Sample no. & Similarity & Sample no. & Similarity \\
\hline S1 & 0.612 & S11 & 0.741 \\
S2 & 0.705 & $\mathrm{~S} 12$ & 0.770 \\
S3 & 0.903 & $\mathrm{~S} 13$ & 0.825 \\
S4 & 0.853 & $\mathrm{~S} 14$ & 0.620 \\
S5 & 0.871 & $\mathrm{~S} 15$ & 0.213 \\
S6 & 0.858 & $\mathrm{~S} 16$ & 0.485 \\
S7 & 0.836 & $\mathrm{~S} 17$ & 0.474 \\
S8 & 0.679 & $\mathrm{~S} 18$ & 0.478 \\
S9 & 0.868 & $\mathrm{~S} 19$ & 0.440 \\
S10 & 0.688 & $\mathrm{~S} 20$ & 0.539 \\
\hline
\end{tabular}

\subsubsection{Hierarchical Clustering Analysis (HCA)}

The concepts of dissimilarity and similarity are basic to cluster analysis. HCA was performed with the aid of SPSS software version 16, USA. The peaks areas of all the samples were systematically clustered and the Ward method and Squared of the Euclidean distance were selected as a measure of similarity between samples of different batches. In addition, the reliability and accuracy of chromatographic fingerprints using similarity calculations were further demonstrated by HPLC-based. HCA, a widely used technique for differentiating herbal plant species, exhibited the relationships between the twenty samples collected from various regions (Figure 8). All the twenty samples including six samples of batch of $C$. distans, seven samples of $C$. citratus, one sample of Imperata cylindrica and six samples C. flexuosus were grouped into three main classes or clusters; the six samples of C. distans (S15- S20) were classed into group one, samples of C. flexuosus with batch numbers (S9- S13) were classed into the second group and two additional samples with batch number S14 corresponded to Imperata cylindrica and one sample of $C$. citratus with batch number $\mathrm{S} 2$ were also classed into the second group. The HCA also shows the high similarity between these three species found in the second group. The third class encompasses sample of $C$. citratus with batch number S1, S3, S4, S5, S6, S7 and one sample of $C$. flexuosus with batch number S8. Given the characteristics of the regions, HCA could show significant difference between C. distans from its adulterants. Consequently, the obtained results from HCA are consistent with that of the SA.

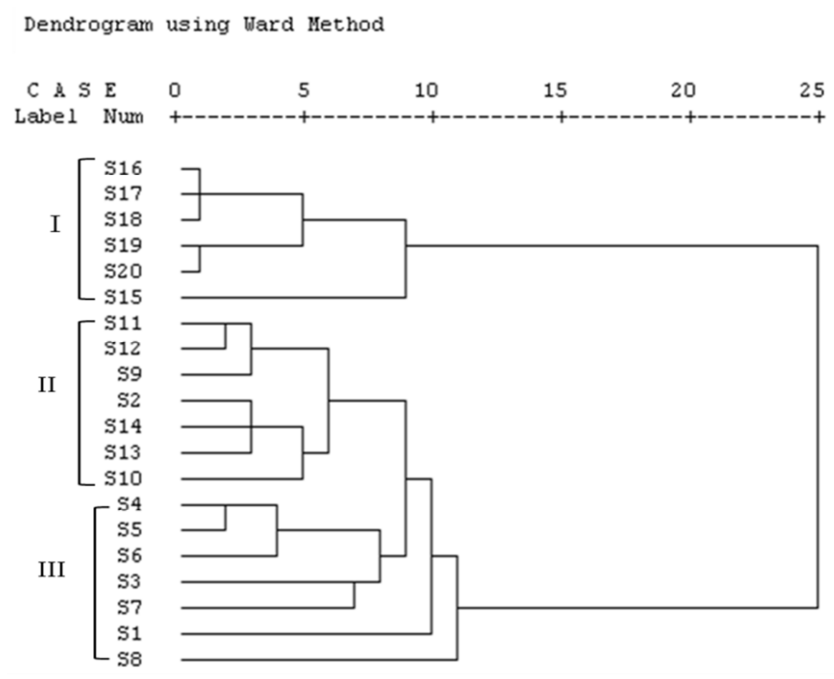

Figure 8. Dendrogram of cluster analysis of C. distans and its adulterants.

\section{Discussion}

In many prior investigations, the identification techniques of medicinal plants such as C. citratus, Imperata cylindrica and $C$. flexuosus have been mainly focused on characterization of morphology, it is challenging to recognize C. distans and its adulterants by experienced or trained experts based on their morphological characteristics. Recently, molecular techniques such as DNA barcoding have been successfully utilized for accurate and rapid identification of 
species, diversity and ecological studies [14], with the ITS2 barcode demonstrating noticeable stability and accuracy in this area. ITS2 has been successfully utilized in researches of identifying medicinal species and their closely related species, as result, lots of medicinal species like Rosaceae, Ephedrae herba and Corni Fructus have been effectively identified using ITS2 sequence [26-29]. According to Hou et al. [29], ITS2 region was proven to successfully differentiate Corni Fructus from its adulterants. Xin et al. [30] indicated that the ITS2 barcode as a powerful tool for tracing Goji. Their results also showed that this technique precisely identify Ephedrae herba and their closely related species [27]. The ITS2 region has also been used by other authors for identification, for example, for spider mites [31], for sycophila [32], for Corydalis boweri [33], Meconopsis horridula and their closely related species of the same genus, and for Fasciola [34]. Furthermore, ITS1 was used to reveal that species of Amomum villosum belongs to the family Zingiberaceae [35].

In contrast to other reports, this investigation provides a strong case for the combination of microscopic evaluation, HPLC fingerprint and ITS2 region being the most promising universal techniques for validating $C$. distans and their closely related species, and adulterants. In molecular identification, despite the fact that plants share many morphological similarities, ITS2 region was found not only able to differentiate plant taxa from diverse plant species but also capable to discriminate closely related taxa at the genus and species stages, suggesting that ITS2 as DNA barcorde in plants is a suitable technology for distinguishing the species $C$. distans, even though ITS2 has been extensively used to distinguish the medicinal species. These findings were in consistent with above studies who also demonstrated variation for closely-related species. This study obviously demonstrates that DNA barcoding using candidate like ITS2 is a reliable method for differentiating $C$. distans from the other plant species, which can also be applied to rapid identification of medicinal plants and their adulterants or substitutes.

Previous studies have reported that microscopic assessment to be helpful for the quality control of plant species including C. citratus and discrimination from drugs and adulterants [36]. E.L. Kotina et al. [37] studied the anatomical characteristics of leaves of Warburgia salutaris (Canellaceae). Eltahir and al. [38] demonstrated that the number of spongy parenchyma cells and the quantities of oil detected in the leaf epidermal cells of $C$. citratus could make the difference between $C$. citratus and Cymbopogon schoenanthus and avoid adulteration. In this study, the microscopic assessment of $C$. distans showed that the spongy parenchyma is constituted of 1-2 layers in C. citratus followed by the upper epidermis, while the lower epidermis in $C$. distans is constituted of one layer of small cell following by the spongy mesophyll that is located between vascular bunbles.

Finally, the fingerprint chromatograms of 6 lots of $C$. distans collected from different provinces showed that the similarity between all species were all more than 0.91 except S15 collected in Sichuan Province, which was affected by local ecological environmental factors and the fingerprint chromatograms of 6 batches of C. flexuous from different provinces indicated that all samples were all more than 0.91 and the result showed that chemical composition of $C$. flexuous collected in different province shared similar HPLC fingerprints. In addition, the similarity of 7 batches of $C$. citratus showed that 5 samples were all more than 0.91 and two samples S1 and S2 were less than 09 indicating that the samples were also unstable. 14 peaks were common between C. distans, C. citratus, C. flexuous and Imperata cylindrica and the similarity were all less than 0.93 . The result showed the great differences between $C$. distans and its adulterants.

\section{Conclusions}

In conclusion, molecular, chemical fingerprint and microscopic analysis were used to evaluate the authentication, quality and safety of $C$. distans from its adulterants. ITS2 was found to be the suitable barcode for identification and could discriminate the $C$. distans species from its adulterants. For microscopic analysis, both the morphology and anatomy structures could distinguish $C$. distans species based on the measurement given in Flora of China and can also be used for screening $C$. distans and its adulterants and closely related species. The study also showed that HPLC fingerprint of 6 batches of $C$. distans, 7 batches of $C$. citratus, and 6 batches of C. flexuosus from different regions were successfully assessed by similarity evaluation and HCA methods. For chemical fingerprint analysis, 30 peaks of all the 6 batches of $C$. distans were assigned as "common peaks", and 27 peaks were common among the 7 batches of $C$. citratus, 21 common peaks were found among 6 batches of $C$. flexuosus and the similarities were all more than 0.93 , indicating that the samples from different geographical origins shared similar HPLC fingerprints. In addition, the chromatogram fingerprint of the twenty collected samples showed the significance difference between $C$. distans and its closely related species, 14 common peaks was found between them; and the similarities were all less than 0.93, demonstrating that HLPC fingerprint was found to be effective in assessing $C$. distans from it adulterant and governing the quality of $C$. distans. Finally, these results indicated that analytical method developed in the current work can be simple and powerful techniques that provide full-scale qualitative and quantitative data for assessing the quality of $C$. distans, and it can also be a valuable reference for the further research and development of this species and its pharmaceutical products.

\section{Acknowledgements}

This work was supported by China Scholarship Council (CSC) Grant \#2014-2018. Also financially supported by Son project of the Investigation of the Background Resources of China Hubei Wufeng Houhe National Natural Reserve (project no. 2017G20001). We also thank Dr. NSENGA KUMWIMBA Mathieu (Chinese Academy of Sciences) for his time and constructive suggestions. 


\section{References}

[1] Baruah, J. B., Gogoi, K Das, N. M Ahmed, DK Sarmah, M. Lal, B.S. Bhau (2017). Genetic diversity study among Cymbopogon species from NE-India using RAPD and ISSR markers. Industrial Crops \& Products 95: 235-243.

[2] Akhila A., Bertea C. M., BigheliA., CasanovaJ., Khunkitti W., Maffei M. E., Mathur A. K., Moyler D. A., Pandey A. K., Sumi H., Tiwari R., Yatagai C., (2009). Essential Oil- Bearing Grasses: The Genus Cymbopogon. Taylor \& Francis Group, New York.

[3] Dou R, Liu Z, Yuan X, Xiangfei D, Bai R, Bi Z, Yang P, Yang Y, Dong Y, Su W, Li D, Mao C. PAMs ameliorates the imiquimod-induced psoriasis-like skin disease in mice by inhibition of translocation of NF- $\mathrm{BB}$ and production of inflammatory cytokines, PLoS One, 2017, 12(5): e0176823

[4] Rao, B. L., (1997). Scope for development of new cultivars of Cymbopogons as a source of terpene chemicals. In: Handa, S. S., Kaul, M. K. (Eds.), Supplement to Cultivation and Utilization of Aromatic Plants. National Institute of Science Communication, Dr. KS. Krishnan Marg, New Delhi, India, pp. $71-83$

[5] Kool A, de Boer H. J, Krüger Å, Rydberg A, Abbad A, Björk L, et al. (2012). Molecular identification of commercialized medicinal plants in Southern Morocco. PLOS ONE. 7: e39459. pmid:22761800

[6] Chen S, Pang X, Song J, Shi L, Yao H, Han J, et al. (2014). A renaissance in herbal medicine identification: from morphology to DNA. Biotechnol Adv.32: 1237-1244. pmid:25087935

[7] SchlickSteiner B. C., Steiner F. M., Seifert B., Stauffer C., Christian E., Crozier RH, (2010). Integrative taxonomy: a multisource approach to exploring biodiversity. Annu Rev Entomol.55: 421-438.

[8] Li DZ, Gao LM, Li HT, Wang H, Ge XJ, Liu JQ, et al. Comparative analysis of a large dataset indicates that internal transcribed spacer (ITS) should be incorporated into the core barcode for seed plants. ProcNatlAcad Sci. 2011; 108: 1964119646.

[9] Hollingsworth ML, Clark A, Forrest LL, Richardson JR, Pennington RT, et al. (2009) Selecting barcoding loci for plants: evaluation of seven candidate loci with species-level sampling in three divergent groups of land plants. Molecular Ecology Resources 9: 439-457.

[10] Fazekas AJ, Burgess KS, Kesanakurti PR, Graham SW, Newmaster SG, et al. (2008). Multiple multilocus DNA barcodes from the plastid genome discriminate plant species equally well. PLoS ONE 3: e2802.

[11] CBOL Plant Working Group (2009) A DNA barcode for land plants. Proceedings of the National Academy of Sciences 106: 12794-12797.

[12] Fazekas AJ, Kesanakurti PR, Burgess KS, Percy DM, Graham SW, et al. (2009) Are plant species inherently harder to discriminate than animal species using DNA barcoding markers? Molecular Ecology Resources 9: 130-139.

[13] Hollingsworth PM, Graham SW, Little DP (2011) Choosing and Using a Plant DNA Barcode. PLoS ONE 6(5): e19254. https://doi.org/10.1371/journal.pone.0019254

[14] Chen S, Yao H, Han J, Liu C, Song J, et al. (2010) Validation of the ITS2 region as a novel DNA barcode for identifying medicinal plant species. PLoS ONE 5: e8613.

[15] Yao H, Song J, Liu C, Luo K, Han J, et al. (2010) Use of ITS2 region as the universal DNA barcode for plants and animals. PLoS ONE 5: e13102.

[16] Li DZ, Gao LM, Li HT, Wang H, et al. China Plant BOL Group (2011) Comparative analysis of a large dataset indicates that internal transcribed spacer (ITS) should be incorporated into the core barcode for seed plants. Proc Natl Acad Sci U S A 108(49): 19641-19646.

[17] World Health Organization: Guidelines for the Assessment of Herbal Medicines WHO, Munich, Geneva; 1991.

[18] FDA, (2004). Guidance for industry-botanical drug products. U.S. Food and Drug Administration.

[19] MEA, (2006). Guidanceon quality of herbal medicinal products/traditional herbal medicinal products. European Medicines Agency.

[20] Ram S., Verma, Rajendra C., Padalia, Amit Chauhan, (2013). Introduction of Cymbopogon distans (Nees ex Steud.) Wats to the sub-tropical India: Evaluation of essential-oil yield and chemical composition during annual growth. Industrial Crops and Products 49.858-863.

[21] Amit Chauhan, Ram S. Verma, Rajendra C. Padalia, Rakesh K. Upadhyay\&Janak R. Bahl (2016): Post harvest storage effect on essential oil content and composition of Cymbopogon distans (Nees ex Steud.) Wats., Journal of Essential Oil Research, DOI: 10.1080/10412905.2016.1164762

[22] Zhang JS, Zhao NN, Liu QZ, Liu ZL, Du SS, Zhou L, Deng ZW. Repellent constituents of essential oil of Cymbopogon distans aerial parts against two stored-product insects. J Agric Food Chem. (2011) Sep 28; 59(18):9910-5

[23] Moore P. D., WebbJ. A, Collison M. E., (1991), Pollen analysis. Blackwell scientific publications. Google Scholar

[24] Johansen D. A. Plant microtechnique: Jeffrey's method, McGraw Hill Book Co., New York (NY) (1940), p. 104Google Scholar

[25] Chen Shouliang, Sylvia M. Phillips. ECHINOCHLOA P. Beauvois. Flora of China 22: 515-518. (2006).

[26] Pang X., J. Song, Y. Zhu, H. Xu, L. Huang, and S. Chen, "Applying plant DNA barcodes for Rosaceae species identification," Cladistics, vol. 27, no. 2, pp. 165-170, (2011).

[27] Pang X. H., J. Y. Song, H. B. Xu, and H. Yao, (2012). "Using ITS2 barcode to identify ephedrae herba," China Journal of Chinese MateriaMedica, vol. 37, pp. 1118-1121

[28] Xin T. Y., H. Yao, K. Luo et al., (2012) "Stability and accuracy of the identification of Notopterygii Rhizoma et Radix using the ITS/ITS2 barcodes," Acta Pharmaceutica Sinica, vol. 47, pp. 1098-1105.

[29] Hou D. Y., Song J. Y., Shi L. C., Ma X. C., Xin T. Y., Han J. P., et al., (2013). Stability and accuracy assessment of identification of traditional Chinese material medica using DNA barcoding: a case study on Flos Lonicerae Japonicae. Biomed Res. Int. 2013:549037. 10.1155/2013/549037 
[30] Xin T. Y., Yao H., Gao H. H., Zhou X. Z., Ma X. C., Xu C. Q., et al. (2013). Super food Lycium barbarum (Solanaceae) traceability via an internal transcribed spacer 2 barcode. Food Res. Int. 54, 1699-1704.

[31] Ben-David, T., Melamed, S., Gerson, U., Morin, S., (2007). ITS2 sequences as barcodes for identifying and analyzing spider mites (Acari: Tetranychidae). Experimental and Applied Acarology 41, 169-181

[32] Li, Y., Zhou, X., Feng, G., Hu, H., Niu, L., Hebert, P. D. N., Huang, D., (2010). COI andITS2 sequences delimit species, reveal cryptic taxa and host specificity of fig-associated Sycophila (Hymenoptera, Eurytomidae). Molecular Ecology Resources 10, 31-40.

[33] Dou R, Bi zhen-fei, Bairui-xue, Renyao-yao, Tan rui, Li di quiang, Song liangke, Mao can quan, (2015). "Identification and analysis of corydalis boweri, Meconopsis horridula, and their closely related species of the same genus by using DNA barcode" China Journal of Chinese Materia Medica, 40(8).

[34] Prasad PK, Tandon V, Biswal DK, Goswami LM, Chatterjee A., (2009). Use of sequence motifs as barcodes and secondary structures of Internal Transcribed spacer 2 (ITS2, rDNA) for identification of the Indian liver fluke, Fasciola (Trematoda: Fasciolidae). Bioinformation 3: 314-320.

[35] Qiao C, Han Q, Zhao Z, Wang Z, Xu L, Xu HX. Sequence analysis based on ITS1 region of nuclear ribosomal DNA of Amomum villosum and ten species of Alpinia. J Food Drug Anal 2009; 17:142-5.

[36] Gagan Shah, Maninderjit Kaur, Falgun Dhabiliya, RichaShri. Pharmacognostic Standardization of Cymbopogon citratus (dc.) stapf leaves. Pharmacognosy Journal, May-June 2012, Vol4, Issue 29.

[37] E. L. Kotina, B.-E. Van Wyk, P. M. Tilney, "Anatomy of the leaf and bark of Warburgia salutaris (Canellaceae), an important medicinal plant from South Africa", South African Journal of Botany 94 (2014) 177-181

[38] Ahlam Salih Eltahir and Bouran Ibrahim Abu EReish, Leaf and stem anatomy of Cymbopogon citratus and Cymbopogon schoenanthus in Sudan, J. Chem. Pharm. Res, 2010, 2(4): 766-771. 